\title{
A randomized controlled trial comparing lithium plus valproic acid versus lithium plus carbamazepine in young patients with type 1 bipolar disorder: the LICAVAL study
}

Giovani Missio ${ }^{1 *}$ (D), Doris Hupfeld Moreno ${ }^{1}$, Frederico Navas Demetrio ${ }^{1}$, Marcio Gerhardt Soeiro-de-Souza ${ }^{1}$, Fernando dos Santos Fernandes ${ }^{1}$, Vivian Boschesi Barros ${ }^{2}$ and Ricardo Alberto Moreno ${ }^{1}$

\begin{abstract}
Background: Treatment of bipolar disorder (BD) usually requires drug combinations. Combinations of lithium plus valproic acid (Li/NPA) and lithium plus carbamazepine (Li/CBZ) are used in clinical practice but were not previously compared in a head-to-head trial.

Objective: The objective of this trial was to compare the efficacy and tolerability of Li/NPA versus Li/CBZ in treating type $1 \mathrm{BD}$ in any phase of illness in young individuals.

Methods: LICAVAL was a randomized, unicenter, open-label, parallel-group trial that was conducted from January 2009 to December 2012 in a tertiary hospital in São Paulo, Brazil. Participants were between 18 and 35 years old and were followed up for 2 years. Our primary outcome was the number of participants achieving/maintaining response and remission during the acute and maintenance phases of BD treatment, respectively. Other outcomes assessed were symptom severity and adverse events throughout the study. In the analysis of the primary outcome, we compared groups by using a two-way repeated measures analysis of variance and estimated effect sizes by using Cohen's d.
\end{abstract}

Results: Of our 64 participants, 36 were allocated to Li/NPA and 28 to Li/CBZ. Our sample was composed predominantly of females (66.6\%) and the average age was 27.8 years. A total of 27 (45.0\%) participants had depression, 17 (28.3\%) had mania/hypomania, and 16 (26.7\%) had a mixed state. We found no between-group differences in CGI-BP (Clinical Global Impression Scale modified for use in bipolar disorder) scores $(P=0.326)$ or in any other outcome. Side effects differed significantly between groups only in the first week of treatment $(P=0.021)$, and there were more side effects in the Li/NPA group. Also, the Li/NPA group gained weight $(+2.1 \mathrm{~kg})$ whereas the Li/CBZ group presented slight weight loss $(-0.2 \mathrm{~kg})$.

Conclusion: Our study suggests that LiNPA and Li/CBZ have similar efficacy and tolerability in BD but that Li/CBZ might have metabolic advantages in the long term.

Trial registration: ClinicalTrials.gov identifier: NCT00976794. Registered on September 9, 2009.

\footnotetext{
* Correspondence: giovani.missio@usp.br

${ }^{1}$ Department of Psychiatry, Mood Disorder Unit (GRUDA), University of São

Paulo School of Medicine, Rua Dr. Ovídio Pires de Campos, 785, São Paulo,

SP 05403-010, Brazil

Full list of author information is available at the end of the article
}

(c) The Author(s). 2019 Open Access This article is distributed under the terms of the Creative Commons Attribution 4.0 International License (http://creativecommons.org/licenses/by/4.0/), which permits unrestricted use, distribution, and reproduction in any medium, provided you give appropriate credit to the original author(s) and the source, provide a link to the Creative Commons license, and indicate if changes were made. The Creative Commons Public Domain Dedication waiver (http://creativecommons.org/publicdomain/zero/1.0/) applies to the data made available in this article, unless otherwise stated. 


\section{Introduction}

Effective treatment of bipolar disorder (BD) should treat and prevent mood episodes [1]. Ideally, these goals are to be achieved with monotherapy. However, more than $80 \%$ of patients with BD require drug combinations [2]. A possible strategy is to combine mood stabilizers, such as lithium plus valproic acid (Li/VPA) and lithium plus carbamazepine (Li/CBZ) [3].

These combinations are common in clinical practice and perform better than monotherapy in some patients with BD. However, their comparative efficacy is unknown $[4,5]$.

Li/VPA is a well-established combination. In the landmark BALANCE trial, Li/VPA had more efficacy than VPA alone in maintenance BD treatment [6]. Other trials have reported advantages of Li/VPA versus monotherapy in specific bipolar populations [7-9]. For instance, in a small study, Li/VPA was associated with marked/moderate improvement in eight of nine patients with refractory rapid cycling $\mathrm{BD}$ [7].

$\mathrm{Li} / \mathrm{CBZ}$ also led to increased response rates in rapid cycling $\mathrm{BD}$ compared with $\mathrm{Li}$ or $\mathrm{CBZ}$ alone, according to Denicoff et al. [10]. This combination also has shown benefit among $\mathrm{Li}$ non-responders. In this population, $\mathrm{Li} / \mathrm{CBZ}$ has been associated with fewer relapses and hospitalizations [11-14]. Also, observational studies associated Li/ CBZ with early improvement compared with $\mathrm{Li}$ alone [15].

Besides being efficacious, Li/VPA and Li/CBZ are generally safe and well tolerated. $[5,16]$. As these drugs are metabolized by different pathways, they lack relevant pharmacokinetic interactions $[5,17]$. Also, their combination might be more suitable than antipsychotics in the long term. Although antipsychotics are efficacious in $\mathrm{BD}$, their long-term use is problematic because of metabolic and neurological side effects [18].

Side effects were more frequent with Li/VPA and Li/ CBZ than with VPA or CBZ alone in some studies [13]. However, in other studies, these combinations were associated with similar or increased tolerability versus monotherapy $[5,6,12,19]$. This might have occurred because $\mathrm{Li} / \mathrm{VPT}$ and $\mathrm{Li} / \mathrm{CBZ}$ have a synergic action, sometimes allowing lower doses of each drug [20]. Another possible explanation is that side effects of one drug were counteracted by those of the other. For instance, Li might reduce CBZ-induced neutropenia [16].

An additional advantage of $\mathrm{Li} / \mathrm{VPA}$ and $\mathrm{Li} / \mathrm{CBZ}$ is that, unlike many first-line $\mathrm{BD}$ treatments, these drugs are cheap and widely available. For instance, patients with BD in Brazil's public health system receive Li, VPA, CBZ, haloperidol, and clorpromazine. Other drugs are usually unavailable for underserved populations, as they can only be obtained out-of-pocket, in academic settings, or under special authorization requests $[21,22]$.
In summary, Li/VPA and Li/CBZ have a favorable efficacy/safety profile in $\mathrm{BD}$ and are of particular importance in underdeveloped countries. However, these combinations were not previously compared in a head-to-head clinical trial. To address this gap in the literature, we designed the LICAVAL study to compare the efficacy and tolerability of Li/VPA versus Li/CBZ in BD.

\section{Methods}

\section{Study design}

LICAVAL was a randomized, unicenter, open-label, parallel-group, equivalence trial comparing the efficacy and tolerability of Li/VPA and Li/CBZ in treating type 1 $\mathrm{BD}$ in young individuals. Participants were allocated in a 1:1 ratio. No changes were made to trial design or outcomes after its commencement. Study reporting followed the Consolidated Standards for Reporting of Trials (CONSORT) statement [23].

\section{Setting}

LICAVAL was designed and implemented by the Mood Disorder Unit (GRUDA) at the Department and Institute of Psychiatry, University of São Paulo Medical School (IPq-FMUSP). IPq-FMUSP is a tertiary referral center located in São Paulo (Brazil).

\section{Ethics}

Our study protocol complied with the Declaration of Helsinki [24]. It was approved by the institutional review board at IPq-FMUSP (protocol number: 0820/08) and registered at www.clinicaltrials.gov (ClinicalTrials.gov identifier: NCT00976794). Study participation was voluntary and required written informed consent. No compensation was involved.

\section{Participants}

Research volunteers were self-selected or referred. Recruitment was made through advertisements at the GRUDA website (www.progruda.com) and posters placed at IPq-FMUSP and other psychiatric units. Our recruitment included individuals who were hospitalized or required hospitalization.

Potential participants were pre-screened through phone interviews and further assessed at GRUDA by using the Structured Clinical Interview for the Diagnostic and Statistical Manual of Mental Disorders-IV-TR Axis I Disorders (SCID-I) [25].

Eligible participants were between 18 and 35 years old and had a diagnosis of type $1 \mathrm{BD}$ in any phase of illness according to the SCID-I. Patients with clinical and psychiatric comorbidities were included as long as these comorbidities were stable. Exclusion criteria were schizophrenia, schizoaffective disorder, unstable clinical illness, and use of antipsychotics or fluoxetine in the previous month. 


\section{Interventions}

Study participants were allocated to receive Li/VPA or Li/CBZ. Participants were assessed weekly in the first month and fortnightly in the second month. Those who had clinical response after 2 months (acute phase of treatment) were assessed monthly for 22 months. Each assessment included all of our diagnostic instruments (see the 'Outcomes' section below). These medications should be administered orally. Li was initiated at $300 \mathrm{mg}$ twice daily and increased weekly by $300 \mathrm{mg} /$ day to reach serum levels between 0.4 and $0.8 \mathrm{mEq} / \mathrm{L}$. VPA was initiated at $250 \mathrm{mg}$ twice daily and increased weekly by $500 \mathrm{mg} /$ day to reach serum levels between 50 and $125 \mu \mathrm{g} / \mathrm{mL}$. CBZ was initiated at $200 \mathrm{mg}$ once a day for the first two days and increased every two days by $200 \mathrm{mg} /$ day to reach serum levels between 8 and $12 \mu \mathrm{g} / \mathrm{mL}$. Adherence was assessed through pill counts. (Participants were asked to bring their prescribed medication during study visits.)

Other medications allowed at the discretion of psychiatrists were lorazepam $0.5-4 \mathrm{mg} /$ day for insomnia and anxiety and sertraline 25-200 mg/day for bipolar depression. Sertraline was allowed only if depressive symptoms persisted after four weeks of study participation. Participants who finished their participation at the LICAVAL study were followed up at GRUDA for four additional visits over 8 weeks.

\section{Outcomes}

Our primary outcome was the number of participants achieving/maintaining response and remission during the acute and maintenance phases of $\mathrm{BD}$ treatment, respectively. Participants' response in the acute phase of treatment was classified as response (symptom severity reduction of at least $50 \%$ with no worsening of symptoms in the opposite pole), no response (symptom severity reduction of less than $50 \%$ ), and loss of response (response followed by symptom severity reduction of less than $50 \%$ in at least one visit or at the physician's discretion). During the maintenance phase, remission was defined as a symptom severity reduction of at least 75\% with no worsening of symptoms in the opposite pole.

According to our study protocol, our secondary outcome was the number of participants achieving BD remission during the maintenance phase of treatment. However, our sample size finishing this phase of the study was insufficient for this analysis. Thus, we decided to include other outcomes of interested of interest as secondary outcomes: (1) BD severity according to the Clinical Global Impressions Scale modified for use in bipolar disorder (CGI-BP) [26]. The CGI-BP is a Likerttype interviewer-rated instrument that measures severity of $\mathrm{BD}$, ranging from 1 (normal, not ill) to 7 (very severely ill). (2) Symptom severity according to the Hamilton Depression Rating Scale (HAM-D) and the
Young Mania Rating Scale (YMRS). These are validated and widely used interviewer-rated instruments. The HAM-D is a 17-item scale measuring depression severity $[27,28]$. It has Likert-type grading, and scores range from 0 to 52 . The YMRS is an 11-item multiple choice scale that measures manic symptom severity in children and young adults $[29,30]$. Its scores range from 0 to 60 ; (3) Time-to-relapse after the acute phase of treatment; (4) use of medications: mean daily doses and serum levels of Li, VPA, and CBZ and mean daily of sertraline; (5) treatment safety and tolerability according to the Udvalg for Kliniske Undersøgelser (UKU) Side Effect Rating Scale, a 48- item clinician-rated structured interview that assesses side effects of psychotropic medications; (6) time-to-discontinuation due to side effects. At baseline, all participants provided sociodemographic information.

\section{Sample size}

Sample size was calculated on the basis of mean withingroup differences in CGI-BP scores throughout the study. Using the $t$ test, we calculated that a sample size of 50 participants (25 per group) would give us $80 \%$ power to detect a standard deviation of 0.8 (at a level of statistical significance of $5 \%$ ). As our study is an exploratory study, we considered this an appropriate effect size.

\section{Randomization}

We used simple randomization with an allocation ratio of $1: 1$. Study participants were randomly assigned prior to their first study visit. To prevent selection bias, our random sequence was known by administrative staff only. These staff members were responsible for the following tasks during our study: randomization implementation, visit scheduling, and pill counting. They had no other participation in our study design, implementation, or data analysis.

\section{Blinding}

Our study was open-label. Participants and psychiatrists knew which treatment was being administered. To reduce information bias, outcomes were assessed by blinded raters who had no contact with study records.

\section{Statistical methods}

All analysis were performed by using the IBM SPSS Statistics software version 22 (IBM, Armonk, NY, USA). Significance level was 0.05 .

We started our analysis by evaluating central tendency, dispersion, and distribution of all variables. Missing data were imputed through last observation carried forward. Groups were compared with an intention-to-treat approach, but we analyzed only data from participants with at least two visits. 
In the evaluation of the primary outcome, we used a two-way repeated measures analysis of variance to analyze between-group differences in scores from the CGI-BP in the acute phase of study. Effect sizes were estimated by using Cohen's d. Other between-group comparisons were performed by using the $t$ test for continuous variables and the Fisher exact test or the chi-squared test for categorical variables.

We also used Kaplan-Meier curves to analyze timeto-relapse and time-to-discontinuation due to side effects in each group. Curves were then compared by using the log-rank test (Mantel-Cox).

\section{Results}

\section{Participants}

Our study was conducted from January 2009 to December 2012, including patient recruitment. After screening, 64 participants were included: $36(56.3 \%)$ in the Li/VPA group and $28(43.8 \%)$ in the Li/CBZ group (see participant flow in Fig. 1). Owing to withdrawal of consent, four patients were excluded before any treatment (three in the Li/VPA group and one in the Li/CBZ group).

Our sample (Table 1) was composed predominantly of females $(66.6 \%)$ and the average age was 27.8 years. A total of 27 (45.0\%) participants had depression, 17 (28.3\%) had mania/hypomania, and $16(26.7 \%)$ had a mixed state.

\section{Outcomes and estimation}

\section{Clinical impression}

Study participants had a significant reduction in scores from the CGI-BP, our primary outcome (Fig. 2). Effect sizes were high in the Li/VPA group $(P=0.001$; $\mathrm{d}$ Cohen $=0.80)$ and average in the Li/CBZ group $(P=0.058$; $\mathrm{d}$ Cohen $=0.53)($ Table 2$)$. Between-group differences were not significant $(P=0.326)$.

CGI-BP - Depression scores were significantly reduced in both groups. The reduction was higher in the Li/VPA group $(P=0.005 ; \mathrm{d}$ Cohen $=0.84)$ than in the Li/CBZ group $(P=0.014 ; 0.61)$, but between-group differences were not significant $(P=0.898)$.

CGI-BP - Mania scores also had a significant reduction in the Li/VPA group $(P=0.001$; d Cohen $=0.77)$, and the effect size was large. In the $\mathrm{Li} / \mathrm{CBZ}$ group, we found a non-significant reduction in CGI-BP scores $((P=0.152$; $\mathrm{d}$ Cohen $=0.41)$, and effect sizes were average. Betweengroup differences were not significant $(P=0.175)$.

\section{Symptom severity}

The Li/VPA and Li/CBZ groups had a significant reduction in depression scores according to the HAM-D (Fig. 3). Effect sizes were very large. The mean reduction was higher in the Li/CBZ group $(P<0.001 ; \mathrm{d}$ Cohen $=1.51)$ than in the Li/VPA group $(P<0.001 ; \mathrm{d}$ Cohen $=1.10)$,

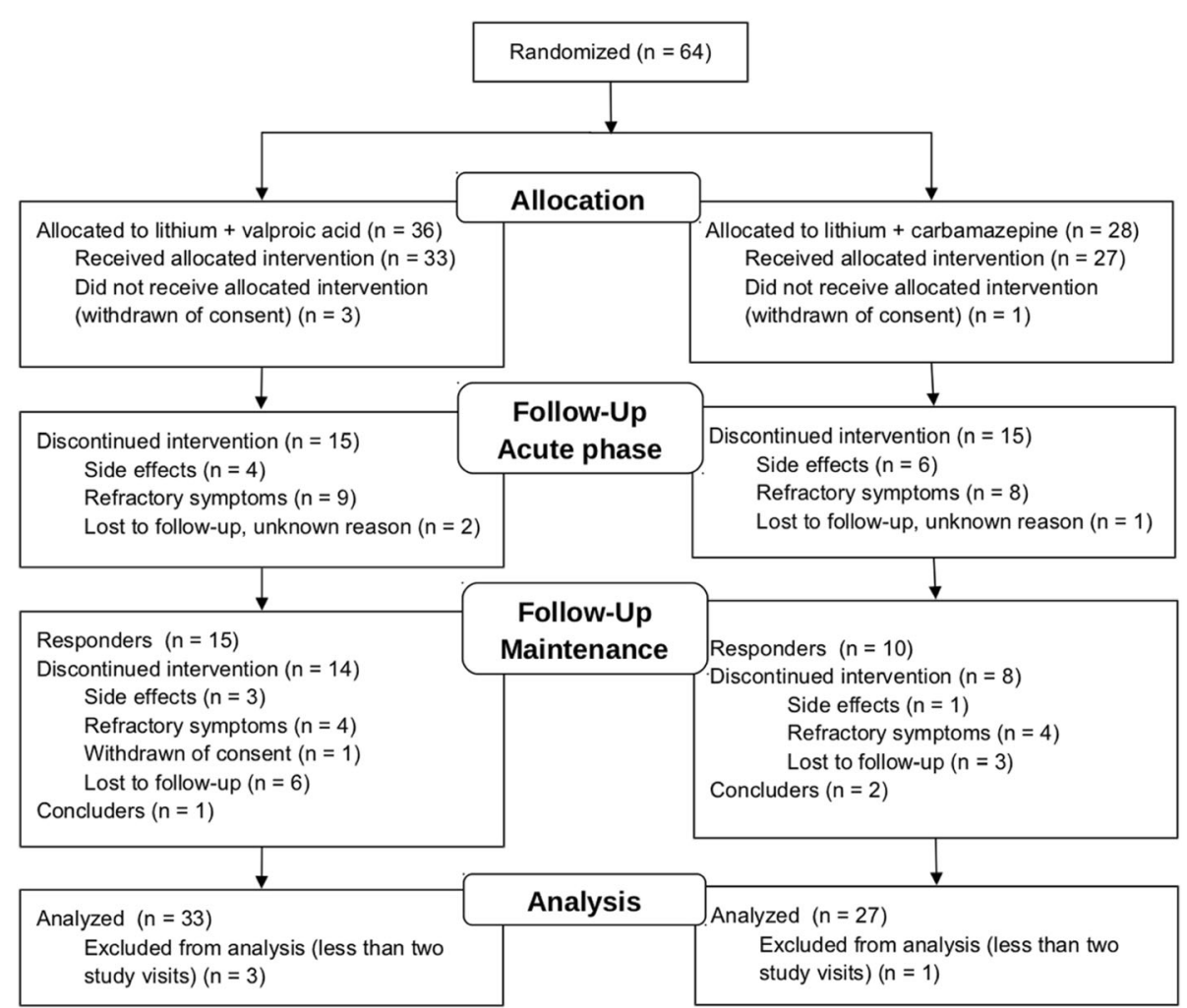

Fig. 1 Consolidated Standards for Reporting of Trials (CONSORT) flow diagram 
Table 1 Baseline sample characteristics

\begin{tabular}{|c|c|c|c|c|}
\hline Variable & Total $(n=60)$ & LiNPA $(n=33)$ & $\mathrm{Li} / \mathrm{CBZ}(n=27)$ & $P$ value \\
\hline Female, $n(\%)$ & $40(66.7 \%)$ & $26(78.8 \%)$ & $14(51.8 \%)$ & $0.05 *$ \\
\hline Age, mean (standard deviation (SD), range) & $27.8(5.1,18-35)$ & $27.5(4.7,18-35)$ & $28.3(5.7,18-33)$ & $0.57^{* *}$ \\
\hline Age at illness onset, mean (SD, range) & $20.4(6.9,5-35)$ & $20.0(7.1,5-30)$ & $20.9(6.7,13-5)$ & $0.72^{* *}$ \\
\hline Weight in kg, mean (SD) & $71.3(14.4)$ & $73.2(14.1))$ & & $0.09 *$ \\
\hline \multicolumn{5}{|l|}{ Current mood, $n(\%)$} \\
\hline Depression & $27(45.0 \%)$ & $13(39.4 \%)$ & $14(51.9 \%)$ & $0.57^{* *}$ \\
\hline Mania/hypomania & $17(28.3 \%)$ & $11(33.3 \%)$ & $6(22.2 \%)$ & \\
\hline Mixed state & $16(26.7 \%)$ & $9(27.3 \%)$ & $7(25.9 \%)$ & \\
\hline \multicolumn{5}{|l|}{ Clinical Global Impressions Scale modified for use in BP, mean (SD, range) } \\
\hline Overall & $3.8(1.1,1.0-6.0)$ & $3.8(1.1,2.0-6.0)$ & $3.8(1.0,1.0-6.0)$ & $0.84 * *$ \\
\hline Depression & $3.3(1.6,0.0-6.0)$ & $3.2(1.5,0.0-6.0)$ & $3.4(1.8,0.0-6.0)$ & $0.62 * *$ \\
\hline Mania/hypomania & $2.8(1.6,1.0-6.0)$ & $3.2(1.7,1.0-6.0)$ & $2.4(1.3,1.0-5.0)$ & $0.07^{* *}$ \\
\hline Manic symptoms (Young Mania Rating Scale) scores, mean (SD, range) & $20.4(7.2)(5.0-39.0)$ & $19.3(7.1,8.0-35.0)$ & $21.6(7.3,5.0-39.0)$ & $0.22 * *$ \\
\hline Depressive symptoms (Hamilton Depression Rating Scale), mean (SD, range) & $11.3(5.9,2.0-28.0)$ & $11.5(6.0,2.0-24.0)$ & $11.1(5.9,4.0-28.0)$ & $0.81 * *$ \\
\hline
\end{tabular}

Li/VPA: lithium plus valproic acid group

Li/CBZ: lithium plus carbamazepine group

*Determined by the Fisher exact test.

**Determined by the student $t$ test.

but between-group differences were not statistically significant $(P=0.359)$.

Similarly, both groups had significant reduction in mania scores according to the YMRS. Effect sizes were medium. Differences were higher in the $\mathrm{Li} / \mathrm{CBZ}$ group $(P=0.023 ; \mathrm{d}$ Cohen $=0.65)$ than in the Li/VPA group $(P=0.041 ; \mathrm{d}$ Cohen $=0.47)$, but again between-group differences were not significant.

\section{Clinical response and time-to-relapse}

Regarding our primary outcome, we found a response rate of $43.3 \%$ and no significant between-group differences. In the acute phase of treatment, treatment response was obtained by $15(45.5 \%)$ of 33 participants in the Li/VPA group and $10(37.0 \%)$ of 27 in the Li/CBZ group $(P=0.602)$.

Responders were followed-up for 22 months, during which $25 \%$ had remission of BD symptoms. In this period, remission was achieved by 10 (37.0\% of 27) of 15 and 6 (22.2\% of 27) of 10 participants in the Li/VPA and Li/CBZ groups, respectively. Time-to-relapse curves were not significantly different between groups $(P=0.455)$ (Fig. 4).

\section{Use of medications}

Li doses and serum levels were not significantly different between groups $(P=0.562)$. In the Li/VPA group, Li doses were $1024 \mathrm{mg}$ (standard deviation $(\mathrm{SD})=324.3$ ) and

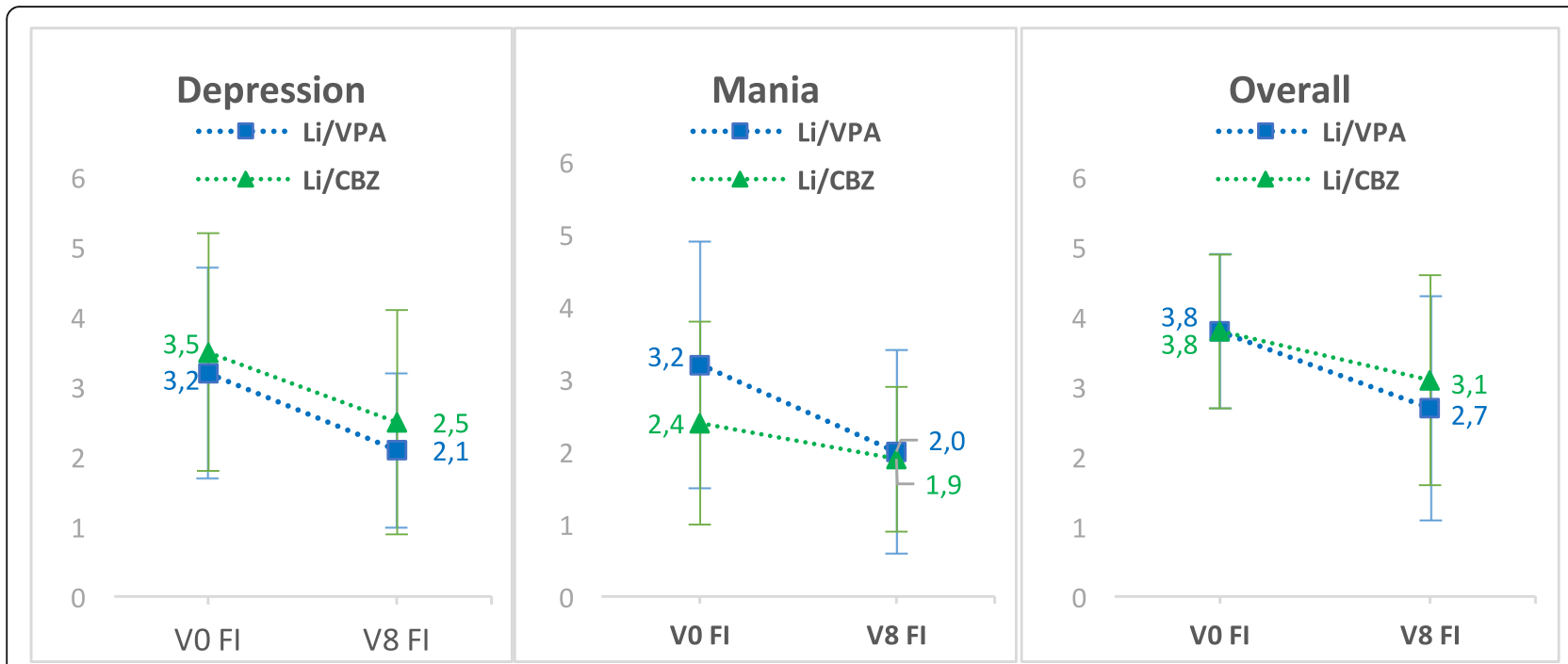

Fig. 2 Mean Clinical Global Impression Scale (CGI) scores per group at baseline and after 8 weeks in the LICAVAL study 
Table 2 Outcome assessment (total and by group)

\begin{tabular}{|c|c|c|c|}
\hline Variable & Li/NPA group & Li/CBZ group & $P$ value \\
\hline Clinical Global Impressions Scale modified for use in BP (CGI-BP) & & & $0.33^{* *}$ \\
\hline Week 0 , average (standard deviation (SD)) & $3.8(1.1)$ & $3.8(1.1)$ & \\
\hline Week 8 , average, SD & $2.7(1.6)$ & $3.1(1.5)$ & \\
\hline Within-group difference, $P$ value*, Cohen's $d$ & $0.001,0.80$ & $0.057,0.53$ & \\
\hline CGI-BP - Depression & & & $0.89^{* *}$ \\
\hline Week 0 , average (SD) & $3.2(1.5)$ & $3.5(1.7)$ & \\
\hline Week 8, average (SD) & $2.1(1.1)$ & $2.5(1.6)$ & \\
\hline Within-group difference $P$ value*, Cohen's $d$ & $0.005,0.84$ & $0.014,0.61$ & \\
\hline CGI-BP - Mania & & & $0.18^{* *}$ \\
\hline Week 0 , average (SD) & $3.2(1.7)$ & $2.0(1.4)$ & \\
\hline Week 8, average (SD) & $2.4(1.4)$ & $1.9(1.0)$ & \\
\hline Within-group difference, $P$ value*, Cohen's $d$ & $0.001,0.77$ & $0.152,0.41$ & \\
\hline Depressive symptoms (Hamilton Depression rating Scale) & & & $0.36^{* *}$ \\
\hline Week 0 , average (SD) & $19.2(7.2)$ & $21.6(7.3)$ & \\
\hline Week 8, average (SD) & $11.3(7.2)$ & $11.5(6.0)$ & \\
\hline Within-group difference, $P$ value*, Cohen's $d$ & $<0.001,1.10$ & $<0.001,1.51$ & \\
\hline Manic symptoms (Young Mania Rating Scale) & & & $0.68^{* *}$ \\
\hline Week 0 , average (SD) & $11.4(6.2)$ & $11.1(5.9)$ & \\
\hline Week 8, average (SD) & $8.7(5.3)$ & $7.5(5.2)$ & \\
\hline Within-group difference, $P$ value*, Cohen's $d$ & $0.041,0.47$ & $0.023,0.65$ & \\
\hline Treatment response in 2 months, $\mathrm{n}(\%)$ & $15(45,5 \%)$ & $10(37,0 \%)$ & $0.61^{* *}$ \\
\hline Treatment remission in 22 months, $\mathrm{n}(\%)$ & $9(27.2 \%)$ & $6(22.2 \%)$ & $0.77^{* *}$ \\
\hline
\end{tabular}

Li/VPA: lithium plus valproic acid group

Li/CBZ: lithium plus carbamazepine group

* Determined by the paired sample $t$ test.

** Determined by the two-way repeated measures analysis of variance.
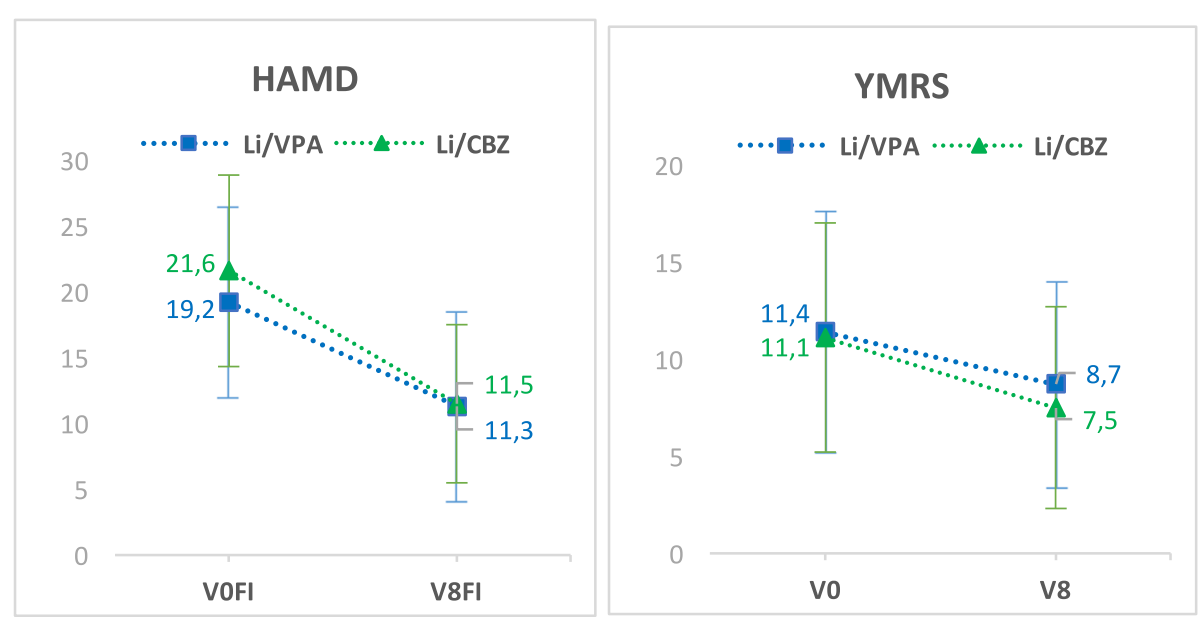

Fig. 3 Hamilton Depression Rating Scale and Young Mania Rating Scale - scores per group at baseline and after 8 weeks in the LICAVAL study 


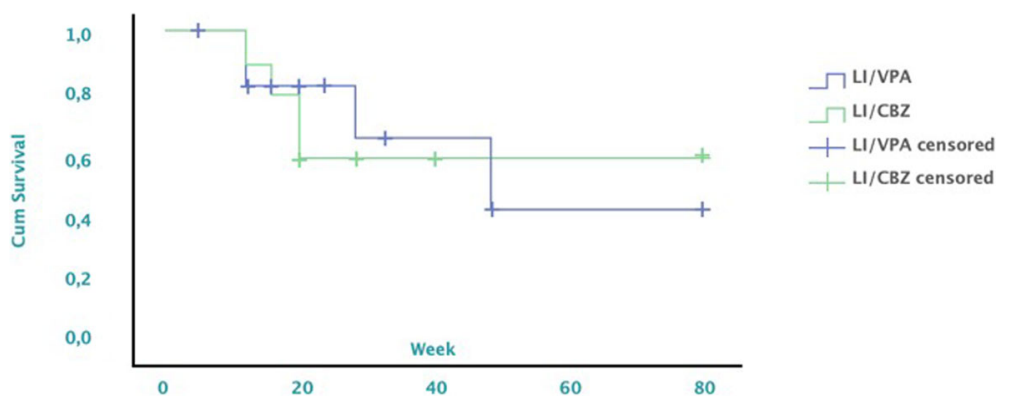

Fig. 4 Cumulative survival per group in the LICAVAL study

serum levels were $0.71 \mathrm{mEq} / \mathrm{L}(\mathrm{SD}=0.22)$. In the $\mathrm{Li} / \mathrm{CBZ}$ group, $\mathrm{Li}$ doses were $989.6 \mathrm{mg}(\mathrm{SD}=284.8)$ and serum levels were $0.64 \mathrm{mEq} / \mathrm{L}(\mathrm{SD}=0.39)$.

The Li/VPA group had a mean dose of VPA of 1003 $\mathrm{mg}(\mathrm{SD}=393)$ and a mean serum level of $70.35 \mathrm{mg}$ $(\mathrm{SD}=20.87)$. The Li/CBZ group had a mean dosage of $\mathrm{CBZ}$ of $586 \mu \mathrm{g} / \mathrm{dL}(\mathrm{SD}=255)$ and a mean serum level of $5.66 \mu \mathrm{g} / \mathrm{dL}(\mathrm{SD}=1.65)$.

Ten participants required sertraline, six in the Li/VPA group and four in the Li/CBZ group. Use of sertraline was different between groups only in week $20(P=0.037)$. In this week, the Li/CBZ group had a higher mean dosage of sertraline (50.0, $\mathrm{SD}=70.7)$ than the group Li/VPA group. There were no significant differences in use of sertraline in other periods of the study.

\section{Safety and tolerability}

Side effects differed significantly between groups in the first week of treatment $(P=0.021)$. In this period, the $\mathrm{Li} / \mathrm{VPA}$ group presented a higher mean number of adverse events per participant than the Li/CBZ group: 3.30 $(\mathrm{SD}=4.65)$ versus $5.63(4.21)$, respectively. In other periods of the study, we found no significant betweengroup differences in adverse events.

According to the UKU Side Effect Rating Scale (Table 3), the Li/VPA group had higher frequencies of fatigue $(P=0.015)$, weight gain $(P=0.013)$, and decreased sexual desire $(P=0.036)$. The $\mathrm{Li} / \mathrm{CBZ}$ group had increased rates of diarrhea $(P=0.001)$.

Weight variation from baseline to week 8 was significantly different between groups $(P=0.047)$. In the $\mathrm{Li} / \mathrm{CBZ}$ group, five participants lost weight. The average weight loss in this group was $0.2 \mathrm{~kg}$ ( 0.44 pounds, $P$ value for the within-group difference $=0.001$ ). In the Li/VPT group, participants gained $2.1 \mathrm{~kg}$ on average (4.63 pounds, $P$ value $=0.03$ ).

Only one serious adverse event occurred during the study: a participant in the Li/CBZ group had severe diarrhea. Given the severity of this adverse event, we decided to withdraw the patient from our study. Patient's diarrhea remitted after Li/CBZ were discontinued. Despite this, we could not confirm its etiology or relationship with these drugs. We had no reports of Li-associated neurological, thyroidean, or renal adverse events.

A total of 14 participants discontinued treatment because of side effects. Seven were in the Li/VPA group (four in the acute phase and three in the maintenance phase), and seven were in the Li/CBZ group (six in the acute phase and one in the maintenance phase). We found no significant between-group differences in curves of time-to-discontinuation due to side effects $(P=0.709)$.

\section{Discussion}

To our knowledge, this is the first head-to-head comparison of $\mathrm{Li} / \mathrm{VPA}$ versus $\mathrm{Li} / \mathrm{CBZ}$ in $\mathrm{BD}$. Our findings indicate that, for young adults with $\mathrm{BD}, \mathrm{Li} / \mathrm{VPA}$ and $\mathrm{Li} /$ CBZ have similar efficacy in acute treatment and relapse prevention over 2 years. One strength of our study is that we had participants in all phases of $\mathrm{BD}$, as in a realworld setting.

We found response and remission rates of $43.3 \%$ and $25 \%$, respectively, and no significant between-group differences. These rates are lower than those reported in some studies. For instance, in the BALANCE trial, remission occurred in around $45 \%$ of participants receiving Li/VPT in a 2-year follow-up [6]. Also, Denicoff et al. reported marked/moderate CGI-BP improvement in around $55 \%$ of participants in one year [10]. Our results probably reflect the characteristics of our sample. Participants of LICAVAL were essentially a convenience sample from a tertiary referral hospital. This population

Table 3 Side effects according to the UKU Side Effect Rating Scale (total and by group)

\begin{tabular}{lllll}
\hline Side effect & Total, $n(\%)$ & LiNPA, $n(\%)$ & Li/CBZ, $n(\%)$ & $P$ value \\
\hline Fatigue & $10(19.5 \%)$ & $8(26.7 \%)$ & $2(8.3 \%)$ & $0.02^{*}$ \\
Decreased sex drive & $8(11.1 \%)$ & $7(20.0 \%)$ & $1(4.2 \%)$ & $0.04^{*}$ \\
Diarrhea & $9(17.7 \%)$ & $2(6.3 \%)$ & $7(29.2 \%)$ & $0.001^{*}$ \\
Weight gain & $49(90.7 \%)$ & $30(100.0 \%)$ & $19(79.2 \%)$ & $0.013^{*}$ \\
\hline
\end{tabular}

* Determined by the Fisher exact test. 
tends to be more difficult to treat, explaining our relatively low response and remission rates.

As our study indicates that $\mathrm{Li} / \mathrm{VPA}$ and $\mathrm{Li} / \mathrm{CBZ}$ have similar efficacy, choosing between these combinations depends greatly on their tolerability. In acute treatment, $\mathrm{Li} / \mathrm{CBZ}$ seemed better tolerated by our sample (fewer side effects). Also, surprisingly, the Li/CBZ group had a slight weight reduction over time whereas the $\mathrm{Li} /$ VPA group gained weight. Weight gain is frequent in BD treatment and is a cause of treatment abandonment [31, 32]. We are unaware of previous studies associating CBZ with weight loss. In the literature, both CBZ and VPT were associated with slight weight gain whereas Li seems neutral [33].

Based on our findings, we hypothesize that $\mathrm{Li} / \mathrm{CBZ}$ has a metabolic advantage compared with Li/VPA and perhaps $\mathrm{CBZ}$ alone. In the long term, this metabolic advantage might be associated with an increase in treatment adherence and with a decrease in metabolic syndrome and cardiovascular disease rates. Thus, although Li/CBZ and Li/VPA have a similar efficacy in our study, Li/CBZ might be more effective and efficient in treating BD [34]. However, we must acknowledge that our side effect analysis was not corrected for multiple comparisons. Also, LICAVAL was not powered to compare side effect rates between groups.

Despite its relevance, our study has limitations. First, our sample was composed mainly of patients from a tertiary referral center. These patients likely have more severe and refractory $\mathrm{BD}$ than the general population, impairing our study external validity. Despite this limitation, our results should be valid for similar populations. Second, we used sequential allocation, a method that can lead to selection bias. Yet we protected our allocation sequence, which was known only by administrative personnel who had no direct participation in our study. Third, our study was open-label, which might have influenced our results. However, our raters were blinded, reducing bias in outcome assessment. Fourth, we allowed the use of sertraline in depressed participants, which might have impacted the effect of $\mathrm{Li} / \mathrm{VPA}$ or $\mathrm{Li} / \mathrm{CBZ}$ in our participants. We believe this did not affect our results, as sertraline use was not different between study groups. Fifth, only three participants completed the maintenance phase of our study. As previously stated, this prevented us from analyzing treatment outcomes during this phase of BD treatment. Finally, although we calculated a sample size to achieve $80 \%$ power, larger samples might have shown between-group differences.

In conclusion, the results of the LICAVAL study suggest that $\mathrm{Li} / \mathrm{VPA}$ and $\mathrm{Li} / \mathrm{CBZ}$ have similar efficacy and tolerability in $\mathrm{BD}$ but that $\mathrm{Li} / \mathrm{CBZ}$ might have metabolic advantages in the long term. Our results should aid evidence-based decision-making regarding $\mathrm{BD}$ treatments, especially in underdeveloped countries.

\section{Abbreviations}

BD: Bipolar disorder; CBZ: Carbamazepine; CGI-BP: Clinical Global Impression Scale modified for use in bipolar disorder; GRUDA: Mood Disorder Unit; HAM-D: Hamilton Depression Rating Scale; IPq-FMUSP: Psychiatry Institute of University of São Paulo School of Medicine; Li: Lithium; Li/CBZ: Lithium plus carbamazepine; Li/NPA: Lithium plus valproic acid; SCID-I: Structured Clinical Interview for the Diagnostic and Statistical Manual of Mental Disorders-IV-TR Axis I Disorders; SD: Standard deviation; UKU: Udvalg for Kliniske Undersøgelser; VPA: Valproic acid; YMRS: Young Mania Rating Scale

\section{Acknowledgments}

The authors thank Rodolfo Nunes Campos, Domingos Junior Rodrigues dos Santos, Carla Garcia, and Carlos Rodrigues dos Santos for their assistance and contributions to this study.

\section{Authors' contributions}

This study was originally conceived by RAM, who is the principal investigator and was conducted from the middle to the end by GM, who was responsible for statistical analyses. The manuscript was written by GM and VBB and reviewed by RAM. All authors read and approved the final manuscript. GHM, FND, MGS, and FdSF contributed to collect, process and analise data.

\section{Funding}

This study had no specific funding. All medications and structure used for attendance and treatment are normally provided by the Brazilian Public Health System.

\section{Availability of data and materials}

Not applicable.

\section{Ethics approval and consent to participate}

This study was approved by the institutional review board at IPq-FMUSP (protocol number: 0820/08). Written informed consent was obtained from participants after the procedures were fully explained. Study participation was voluntary and no compensation was involved.

\section{Consent for publication}

Not applicable.

\section{Competing interests}

The authors declare that they have no competing interests.

\section{Author details}

'Department of Psychiatry, Mood Disorder Unit (GRUDA), University of São Paulo School of Medicine, Rua Dr. Ovídio Pires de Campos, 785, São Paulo, SP 05403-010, Brazil. ${ }^{2}$ University of São Paulo School of Public Health, Av. Dr. Arnaldo, 715, São Paulo, SP 01246-904, Brazil.

Received: 11 January 2019 Accepted: 13 August 2019

Published online: 26 October 2019

\section{References}

1. Berk M. Neuroprogression: Pathways to progressive brain changes in bipolar disorder. Int J Neuropsychopharmacol. 2009;12:441-5.

2. Fornaro M, De Berardis D, Koshy AS, Perna G, Valchera A, Vancampfort D, et al. Prevalence and clinical features associated with bipolar disorder polypharmacy: A systematic review. Neuropsychiatr Dis Treat. 2016;12:719.

3. Grande I, de Arce R, Jiménez-Arriero MA, Lorenzo FGI, Valverde JIF, BalanzáMartínez $\mathrm{V}$, et al. Patterns of pharmacological maintenance treatment in a community mental health services bipolar disorder cohort study (SINDEPRES). Int J Neuropsychopharmacol. 2013;16:513-23.

4. Keck JP, McElroy SL. Carbamazepine and valproate in the maintenance treatment of bipolar disorder. J Clin Psychiatry. 2002;63:13-7.

5. Granneman GR, Schneck DW, Cavanaugh JH, Witt GF. Pharmacokinetic interactions and side effects resulting from concomitant administration of lithium and divalproex sodium. J Clin Psychiatry. 1996;57:204-6.

6. Geddes JR, Rendell JM, Goodwin GM, investigators B, others. BALANCE: a large simple trial of maintenance treatment for bipolar disorder. World Psychiatry. 2002;1:48. 
7. Sharma V, Persad E, Mazmanian D, Karunaratne K. Treatment of rapid cycling bipolar disorder with combination therapy of valproate and lithium. Can J Psychiatr. 1993;38:137-9.

8. Calabrese JR, Delucchi GA. Spectrum of efficacy of valproate in 55 patients with rapid-cycling bipolar disorder. Am J Psychiatry. 1990;147:431.

9. Reischies FM, Hartikainen J, Berghöfer A. Initial lithium and valproate combination therapy in acute mania. Neuropsychobiology. 2002;46:22-7.

10. Denicoff KD, Smith-Jackson EE, Disney ER, Ali SO, Leverich GS, Post RM Comparative prophylactic efficacy of lithium, carbamazepine, and the combination in bipolar disorder. J Clin Psychiatry. 1997;58:470-8.

11. Bocchetta A, Chillotti C, Severino G, Ardau R, Del Zompo M. Carbamazepine augmentation in lithium-refractory bipolar patients: A prospective study on long-term prophylactic effectiveness. J Clin Psychopharmacol. 1997;17:92-6.

12. Shukla S, Cook BL, Miller M. Lithium-carbamazepine versus lithiumneuroleptic prophylaxis in bipolar illness. J Affect Disord. 1985;9:219-22.

13. Baethge C, Baldessarini RJ, Mathiske-Schmidt K, Hennen J, Berghöfer A, Müller-Oerlinghausen $B$, et al. Long-term combination therapy versus monotherapy with lithium and carbamazepine in 46 bipolar I patients. J Clin Psychiatry. 2005;66:174-82

14. Kramlinger $K$, Post RM. Adding lithium carbonate to carbamazepine: Antimanic efficacy in treatment-resistant mania. Acta Psychiatr Scand. 1989; 79:378-85.

15. Costanzo ED, Schifano F. Lithium alone or in combination with carbamazepine for the treatment of rapid-cycling bipolar affective disorder. Acta Psychiatr Scand. 1991;83:456-9.

16. Freeman MP, Stoll AL. Mood stabilizer combinations: A review of safety and efficacy. Am J Psychiatry. 1998;155:12-21.

17. Müller-Oerlinghausen B. Drug interactions with lithium. CNS Drugs. 1999;11: $41-8$.

18. Arana GW. An overview of side effects caused by typical antipsychotics. J Clin Psychiatry. 2000;61:5-11.

19. Kishimoto A. The treatment of affective disorder with carbamazepine: Prophylactic synergism of lithium and carbamazepine combination. Prog Neuro-Psychopharmacol Biol Psychiatry. 1992;16:483-93.

20. Goodwin FK. Rationale for using lithium in combination with other mood stabilizers in the management of bipolar disorder. J Clin Psychiatry. 2003;64:18-24.

21. Ministério da Saúde brasileiro. Relação Nacional de Medicamentos Essenciais 2017. http://bvsms.saude.gov.br/bvs/publicacoes/relacao nacional_medicamentos_rename_2017.pdf (accessed July 1, 2018).

22. Governo do Estado de São Paulo. Relação estadual de medicamentos do componente especializado da assistencia farmacêutica 2018. http://www. saude.sp.gov.br/ses/perfil/gestor/assistencia-farmaceutica/medicamentosdos-componentes-da-assistencia-farmaceutica/links-do-componenteespecializado-da-assistencia-farmaceutica/relacao-estadual-demedicamentos-do-componente-especializado-da-assistencia-farmaceutica/ consulta-por-medicamento (accessed July 1, 2018)

23. Moher D, Schulz KF, Altman DG. The CONSORT statement: Revised recommendations for improving the quality of reports of parallel-group randomised trials. Lancet. 2001:357:1191-4.

24. General Assembly of the World Medical Association. World Medical Association Declaration of Helsinki: ethical principles for medical research involving human subjects. J Am Coll Dent. 2014;81:14-8.

25. First MB, Spitzer RL, Gibbon M, Williams JB, Del Ben CM, Zuardi AW, et al. Structured Clinical Interview for DSM-IV ${ }^{\otimes}$ Axis I Disorders (SCID-I), Clinician Version, Administration Booklet. New York: American Psychiatric Association; 2013.

26. Spearing MK, Post RM, Leverich GS, Brandt D, Nolen W. Modification of the Clinical Global Impressions (CGI) scale for use in bipolar illness (BP): The CGIBP. Psychiatry Res. 1997;73:159-71.

27. Hamilton M. A rating scale for depression. J Neurol J Neurol Neurosurg Psychiatry. 1960;23:56.

28. Ramos de Carvalho TF, Garcia Lima M, Soares Azevedo RC, Caetano D. Tradução do inglês para o português do questionário de auto-avaliação da Escala de Hamilton para a Depressão. J Bras Psiquiatr. 1993:42:255-60.

29. Young R, Biggs J, Ziegler V, Meyer D. A rating scale for mania: Reliability, validity and sensitivity. Br J Psychiatry. 1978;133:429-35.

30. Vilela J, Crippa J, Del-Ben C, Loureiro S. Reliability and validity of a Portuguese version of the Young Mania Rating Scale. Braz J Med Biol Res. 2005;38:1429-39.

31. Keck PE, McElroy SL. Bipolar disorder, obesity, and pharmacotherapyassociated weight gain. J Clin Psychiatry. 2003;64:1426-35.
32. Johnson FR, Özdemir S, Manjunath R, Hauber AB, Burch SP, Thompson TR. Factors that affect adherence to bipolar disorder treatments: A statedpreference approach. Med Care. 2007;45:545-52.

33. Domecq JP, Prutsky G, Leppin A, Sonbol MB, Altayar O, Undavalli C, et al. Drugs commonly associated with weight change: A systematic review and meta-analysis. J Clin Endocrinol Metab. 2015;100:363-70.

34. Andrews G. Efficacy, Effectiveness and Efficiency in Mental Health Service Delivery. Aust N Z J Psychiatry. 1999. p. 316-22.

\section{Publisher's Note}

Springer Nature remains neutral with regard to jurisdictional claims in published maps and institutional affiliations.
Ready to submit your research? Choose BMC and benefit from:

- fast, convenient online submission

- thorough peer review by experienced researchers in your field

- rapid publication on acceptance

- support for research data, including large and complex data types

- gold Open Access which fosters wider collaboration and increased citations

- maximum visibility for your research: over $100 \mathrm{M}$ website views per year

At $\mathrm{BMC}$, research is always in progress.

Learn more biomedcentral.com/submissions 